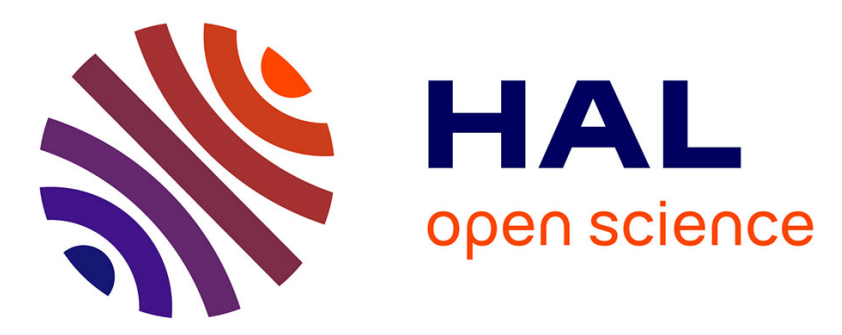

\title{
Production of argon metastable atoms in high pressure (20-300 Torr) microwave discharges
}

\author{
J. Muzart, A. Granier, J. Marec, André Ricard
}

\section{To cite this version:}

J. Muzart, A. Granier, J. Marec, André Ricard. Production of argon metastable atoms in high pressure (20-300 Torr) microwave discharges. Revue de Physique Appliquée, 1988, 23 (10), pp.17491754. 10.1051/rphysap:0198800230100174900 . jpa-00246003

\section{HAL Id: jpa-00246003 https://hal.science/jpa-00246003}

Submitted on 1 Jan 1988

HAL is a multi-disciplinary open access archive for the deposit and dissemination of scientific research documents, whether they are published or not. The documents may come from teaching and research institutions in France or abroad, or from public or private research centers.
L'archive ouverte pluridisciplinaire HAL, est destinée au dépôt et à la diffusion de documents scientifiques de niveau recherche, publiés ou non, émanant des établissements d'enseignement et de recherche français ou étrangers, des laboratoires publics ou privés. 


\title{
Production of argon metastable atoms in high pressure (20-300 Torr) microwave discharges
}

\author{
J. Muzart $\left({ }^{1}\right)$, A. Granier $\left({ }^{2}\right)$, J. Marec $\left({ }^{2}\right)$ and A. Ricard $\left({ }^{2}\right)$ \\ (1) Departamento de Fisica, Universite Federal de Santa Catarina, 88000 Florianopolis (S.C.), Brasil \\ (2) Laboratoire de Physique des Gaz et des Plasmas, Université Paris Sud, Bâtiment 212, 91405 Orsay Cedex
}

(Reçu le 21 mars 1988, révisé le 2 juin 1988, accepté le 30 juin 1988)

\begin{abstract}
Résumé. - La production d'atomes métastables d'argon $\operatorname{Ar}\left({ }^{3} \mathrm{P}_{2}\right)$ a été déterminée dans des décharges microondes de $2.45 \mathrm{GHz}$ à fortes pressions (20 à 300 Torr) et faibles puissances $(5 \mathrm{à} 30 \mathrm{~W})$. Les paramètres suivants du plasma ont été mesurés : la température du gaz, déduite du spectre rotationnel du radical $\mathrm{CN}$ en impureté dans l'argon, est comprise entre $380 \mathrm{~K}$ (20 Torr, $5 \mathrm{~W}$ ) et $840 \mathrm{~K}$ ( $300 \mathrm{Torr}, 30 \mathrm{~W}$ ) ; les concentrations de $\operatorname{Ar}\left({ }^{3} \mathrm{P}_{2}\right)$, notées $n_{\mathrm{M}}$, mesurées par la méthode de l'absorption optique résonnante, sont comprises entre 1 et $5 \times 10^{11} \mathrm{~cm}^{-3}$; la densité électronique $\left(n_{\mathrm{e}}\right)$, mesurée par la variation de phase du champ électrique extérieur, varie de 3 à $20 \times 10^{12} \mathrm{~cm}^{-3}$. Avec un rapport de densités $n_{\mathrm{M}} / n_{\mathrm{e}}$ de 0.065 , le plasma micro-onde à $2.45 \mathrm{GHz}$ apparaît être un milieu gazeux plus ionisé qu'excité.

Abstract. - The production of $\operatorname{Ar}\left({ }^{3} \mathrm{P}_{2}\right)$ metastable atoms has been determined in high pressure (20-300 Torr) and low power $(5-30 \mathrm{~W})$ argon $2.45 \mathrm{GHz}$ microwave discharges. The following plasma parameters have been measured : the gas temperature, deduced from the rotational spectra of $\mathrm{CN}$ radical in impurity in argon, was found between $380 \mathrm{~K}(20$ Torr, $5 \mathrm{~W})$ and $840 \mathrm{~K}(300 \mathrm{Torr}, 30 \mathrm{~W})$; the $\operatorname{Ar}\left({ }^{3} \mathrm{P}_{2}\right)$ concentration $\left(n_{\mathrm{M}}\right)$, measured by the resonant optical absorption method, ranged from 1 to $5 \times 10^{11} \mathrm{~cm}^{-3}$; the electron density $\left(n_{\mathrm{e}}\right)$, measured by the phase variation of the outside electric field, was from 3 to $20 \times 10^{12} \mathrm{~cm}^{-3}$. With a $n_{\mathrm{M}} / n_{\mathrm{e}}$ density ratio of 0.065 , the $2.45 \mathrm{GHz}$ microwave plasma appears to be a more ionized than excited gas medium.
\end{abstract}

\section{Introduction.}

Microwave discharges produced by surface waves $(100-2450 \mathrm{MHz})$ have been extensively studied in low pressure range $\left(10^{-2}-1\right.$ Torr $)$, particularly in argon discharges both from the point of view of wave propagation and of discharge equilibrium conditions [1-2].

Low pressure plasma columns can be sustained in large diameter tubes, typically $2.5 \mathrm{~cm}$. In these conditions the radial distributions of excited species, especially of metastable atoms, have been analysed theoretically and experimentally [3-4]. When the gas pressure is increased from about 20 Torr to atmospheric pressure the microwave discharges exhibit a filamentary appearance and thus become instable in tube which diameter is about $1 \mathrm{~cm}$. To be stabilized the discharge has to be produced in capillary tubes (inside diameter in the $1 \mathrm{~mm}$ range at atmospheric pressure).
In the 20-300 Torr pressure range which has been presently studied, a $2.45 \mathrm{GHz}$ discharge has been stabilized in a quartz tube of $5 \mathrm{~mm}$ internal diameter and $10 \mathrm{~mm}$ external diameter. Under these conditions, the diagnostic of the Ar excited states by optical absorption along the tube axis has been performed. The purpose of this article is to report the concentrations of argon metastable atoms obtained in high pressure and low power $(5-30 \mathrm{~W})$ microwave discharges. We have studied the $\operatorname{Ar}\left({ }^{3} \mathrm{P}_{2}\right)$ metastable level since it is the most populated level of metastable atoms. The electron densities have also been deduced from the phase variation of the electric field measured outside the discharge tube [5].

\section{The experimental setup.}

The experimental setup is shown in figure 1. The $2450 \mathrm{MHz}$ microwave discharge was produced by a 


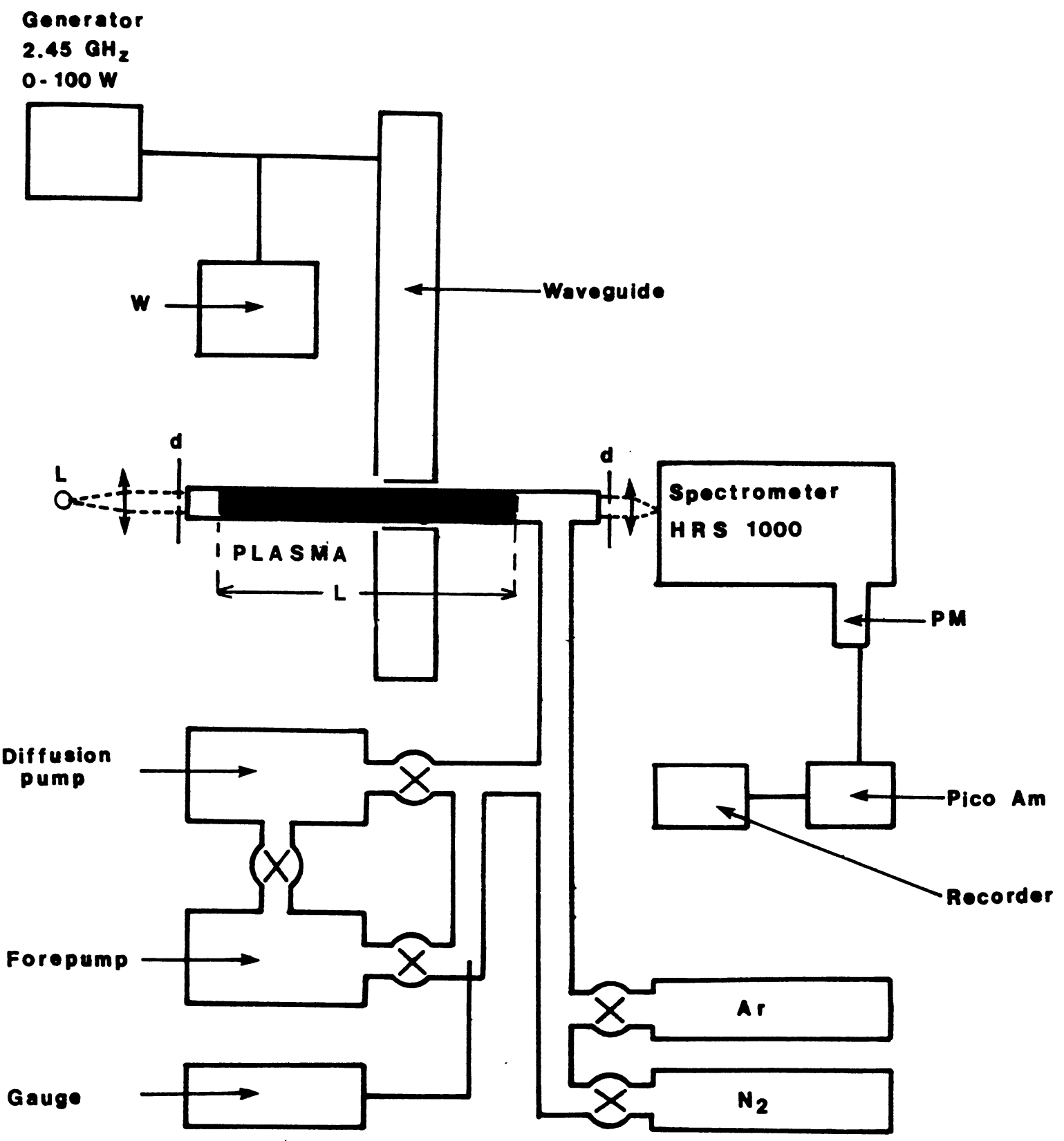

Fig. 1. - Experimental setup : $\mathrm{L}=$ optical source (Ar Philips lamp), $\mathrm{d}$ : Iris diaphragm.

waveguide in the quartz tube (diameter $5 \mathrm{~mm}$ ). The plasma length can be varied from 5 to $15 \mathrm{~cm}$ depending on the argon gas pressure (20-300 Torr) and on the discharge microwave power (5-30 W). The incident and reflected powers were measured with a wattmeter. The densities of the $\operatorname{Ar}\left({ }^{3} \mathrm{P}_{2}\right)$ metastable atoms have been measured by optical absorption. The resonant absorption method of Mitchell and Zemanski [6] has been chosen as being a sensitive optical method. It requires the choice of a convenient spectral line, emitted by a standard optical source (argon Philips lamp), and able to be absorbed by the metastable atoms. The incident light beam has been limited to a diameter of $2 \mathrm{~mm}$ on the tube axis by using two iris diaphragms.
In the Mitchell and Zemanski method the profile of the incident line emitted by the argon optical source and that of the plasma absorption line have been determined. The line profiles of the optical source have been measured with a Fabry-Perot spectrometer (Tropel). In order to determine the absorption line profiles we have to take into account both the Doppler broadening due to the gas temperature and the pressure broadening and line shift due to the high pressure (20-300 Torr) of the argon discharges. Therefore we measure the gas temperature and the pressure which enable us to calculate the absorption line profiles. Knowing the incident and the absorption line profiles, the $\operatorname{Ar}\left({ }^{3} \mathrm{P}_{2}\right)$ metastable densities have been deduced from the exper- 
imental absorption of the total line profile measured with a low resolution $(\delta \lambda=0.1-0.2 \mathrm{~nm})$ optical spectrometer. Obviously, the metastable density we obtain is an averaged value over the plasma length.

\section{Optical absorption measurements.}

3.1 Profile of THE SOURCE LiNE. - The source line intensity $I_{\nu}^{\mathrm{S}}$ has been measured with a FabryPerot spectrometer for two spectral lines: $\operatorname{ArI}$, $\lambda=696.5 \mathrm{~nm}$ and $\operatorname{ArI}, \lambda=706.7 \mathrm{~nm}$. The line profiles are Gaussian and the total intensity of the incident line $I_{0}^{\mathrm{S}}$ can be written as follows :

$$
I_{0}^{\mathrm{S}}=\int_{-\infty}^{+\infty} \mathrm{e}^{-w_{\mathrm{S}}^{2}} \mathrm{~d} w
$$

with $w=2 \pi \nu$

$$
w_{\mathrm{S}}=\frac{2\left(\nu-\nu_{0}\right)}{\Delta \nu_{\mathrm{D}}^{\mathrm{S}}} \sqrt{\operatorname{Ln} 2}
$$

where $\Delta \nu_{\mathrm{D}}^{\mathrm{S}}$ is the halfwidth of the Gaussian (or Doppler) profile and where $\nu_{0}$ is the central line frequency. A typical $I_{\nu}^{\mathrm{S}}$ incident line profile is plotted in figure 2 .

3.2 Profile of ABSORPTION LINE. - The incident line is absorbed by the plasma which the absorption coefficient $k_{\nu}\left(T_{0}, p\right)$ depends on the neutral gas temperature $T_{0}$ and the gas pressure $p$, following the Voigt profile :

$$
k_{\nu}=k_{0} \frac{a}{\pi} \int_{-\infty}^{+\infty} \frac{\mathrm{e}^{-y^{2}}}{a^{2}+\left(w^{\prime}-y\right)^{2}} \mathrm{~d} y
$$

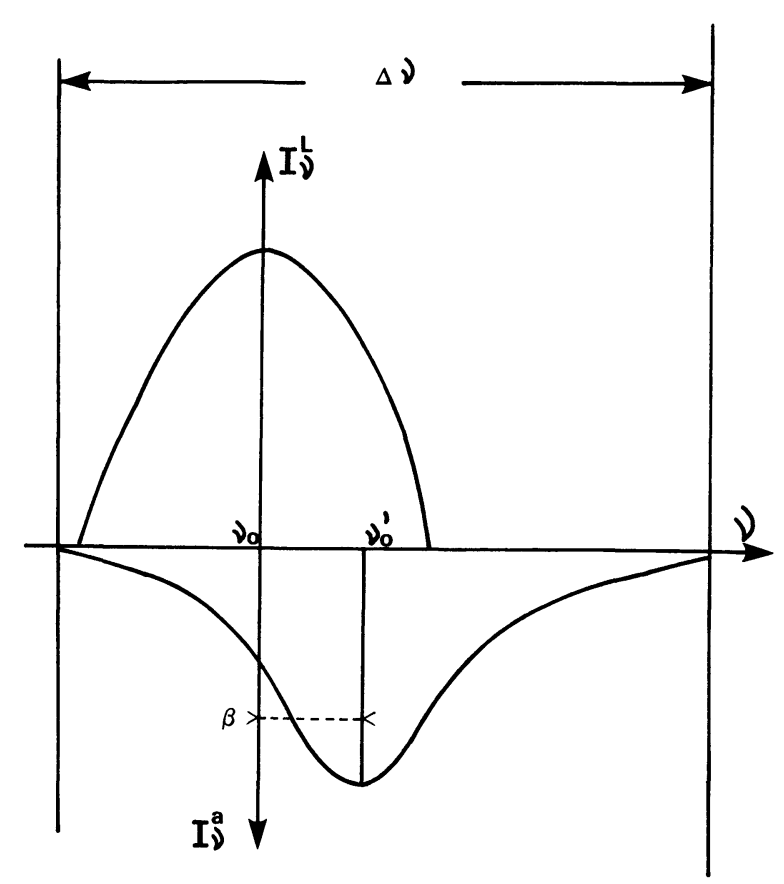

Fig. 2. - Incident $\left(I_{\nu}^{\mathrm{S}}\right)$ and absorption $\left(I_{\nu}^{\mathrm{A}}\right)$ line shapes (schematic diagram). with

$$
\begin{gathered}
k_{0}=\frac{2 e^{2}}{m c} \sqrt{\operatorname{Ln} 2} \frac{n_{\mathrm{M}}}{\Delta \nu_{\mathrm{D}}^{\mathrm{A}}} \\
w^{\prime}=\frac{2\left(\nu-\nu_{0}^{\prime}\right)}{\Delta \nu_{\mathrm{D}}^{\mathrm{A}}} \sqrt{\operatorname{Ln} 2} \\
a=\frac{\Delta \nu_{\mathrm{p}}^{\mathrm{A}}}{\Delta \nu_{\mathrm{D}}^{\mathrm{A}}} \sqrt{\operatorname{Ln} 2}
\end{gathered}
$$

where $\Delta \nu_{\mathrm{D}}^{\mathrm{A}}$ is the plasma Doppler halfwidth, $\Delta \nu_{\mathrm{p}}^{\mathrm{A}}$ is the pressure halfwidth, $n_{\mathrm{M}}$ is the $\operatorname{Ar}\left({ }^{3} \mathrm{P}_{2}\right)$ metastable density, $f$ is the oscillator strength, $\nu_{0}^{\prime}$ the central frequency of the absorption line shifted by the pressure effect $\left(\nu_{0}-\nu_{0}^{\prime}=\beta\right.$ in Fig. 2) and $e, m$ respectively the charge and the mass of the electron and $c$ the light velocity.

The frequency shift $\beta$ and the pressure broadening $\Delta \nu_{\mathrm{p}}^{\mathrm{A}}$ are calculated from published experimental data $[7,8]$. The absorption coefficient $k_{\nu}$ depends on the gas temperature, the pressure and the metastable density. Since the gas temperature and the metastable density are expected to depend on the axial position $z, k_{\nu}$ is also expected to depend on $z$. Nevertheless in our calculation $k_{\nu}$ is considered as constant along the absorption length. Thus we determine a longitudinally averaged metastable density from the measurements of the total absorption $A_{L}$, the neutral temperature $T_{0}$, the gas pressure $p$ and the halfwidth $\Delta \nu_{\mathrm{D}}^{\mathrm{S}}$ of the source line.

We define the total absorption $A_{L}$, over the absorption length $L$, as :

$$
A_{L}=1-I^{\mathrm{S}} / I_{0}^{\mathrm{S}}
$$

where $I^{\mathrm{S}}$ and $I_{0}^{\mathrm{S}}$ are respectively, the total intensity of the source line as the plasma is on and off.

$A_{L}$ is calculated as a function of the metastable density $n_{\mathrm{M}}$, once $\Delta \nu_{\mathrm{D}}^{\mathrm{S}}, \Delta \nu_{\mathrm{D}}^{\mathrm{A}}$ and $\Delta \nu_{\mathrm{p}}^{\mathrm{A}}$ are known :

$$
A_{L}=\frac{\int_{-\infty}^{\infty} \mathrm{e}^{-w_{S}^{2}\left(1-\mathrm{e}^{-k_{\nu} L}\right)} \mathrm{d} w}{\int_{-\infty}^{\infty} \mathrm{e}^{-w_{S}^{2}} \mathrm{~d} w} .
$$

Then $n_{\mathrm{M}}$ is deduced from the relation (4) and measured values of $A_{L}$. The Doppler and pressure halfwidths are determined as follows.

$-\Delta \nu_{\mathrm{D}}^{\mathrm{S}}$ is directly measured on the source

- $\Delta \nu_{\mathrm{p}}^{\mathrm{A}}$ is deduced from the litterature and the pressure measurements

$-\Delta \nu_{\mathrm{D}}^{\mathrm{A}}=7.16 \times 10^{-7} \nu_{0} \sqrt{T_{0} / M}[6]$

where $M$ is the gas molecular weight $(M=40$ for argon gas) and $T_{0}$ is measured under the various experimental conditions as explained in next sections. 


\section{Determination of the gas temperature.}

The plasma temperature has been determined from the rotational spectra of molecules in impurity in argon. In the present high pressure microwave discharges, it has been observed a strong emission of $\mathrm{CN}$ in impurity in argon. The $\mathrm{CN}$ emission was always observed despite the ultimate pressure of $10^{-6}$ torr which has been obtained before the argon gas inlet and despite the high purity of argon in the gas cylinder (less than $10^{-6}$ of impurities). The rotational structure of $\mathrm{CN}\left(\mathrm{B}^{2} \Sigma, V^{\prime}=0 \rightarrow \mathrm{X}^{2} \Sigma\right.$, $\left.V^{\prime \prime}=0\right), \lambda=388.3 \mathrm{~nm}$ has been recorded by using a high resolution spectrometer (Jobin-Yvon HR $1000, \delta \lambda=0.01 \mathrm{~nm}$ ). In the pressure range 20 to 200 Torr and the power range 5 to $30 \mathrm{~W}$, we have found a constant intensity of the $\mathrm{CN}$ emission during about $10 \mathrm{~min}$. in our argon discharges. This time was long enough to record the whole $\mathrm{CN}$ rotational band without intensity variation. A typical rotational spectrum of the $\mathrm{CN}$, P-branch, recorded during 4 min., is shown in figure 3 .

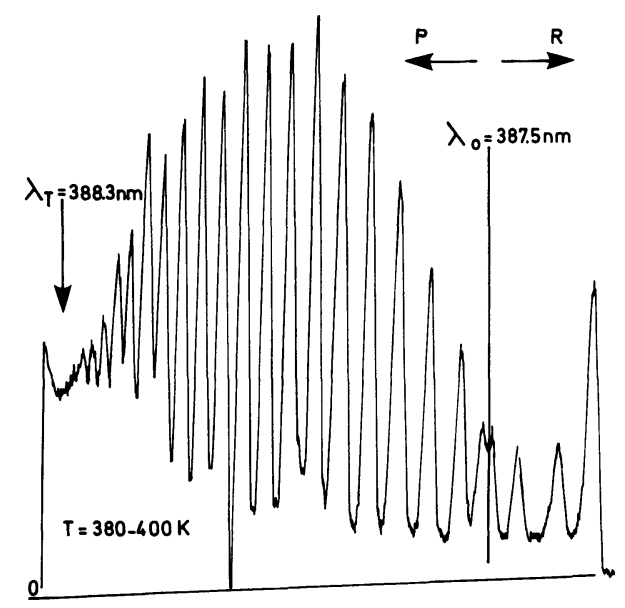

Fig. 3. - Rotational spectrum of the $\mathrm{CN}(\mathrm{B}, \mathrm{O} \rightarrow \mathrm{X}, \mathrm{O})$, $\mathrm{P}$-branch- Band head $=338.3 \mathrm{~nm}$. Ar plasma, $p=20$ Torr. $5 \mathrm{~W}$.

The CN, P-branch intensity is given by the following relation:

$$
I_{J^{\prime}}^{\mathrm{P}}=k_{J^{\prime} J^{\prime \prime}} N_{J^{\prime}} A_{J^{\prime} J^{\prime \prime}} h \nu_{J^{\prime} J^{\prime \prime}}
$$

where $k_{J^{\prime} J^{\prime \prime}}$ is a constant, $N_{J^{\prime}}$ is the density of the upper rotational level $\left(J^{\prime}\right), A_{J^{\prime} J^{\prime \prime}}$ is the radiative emission probability and $h \nu_{J^{\prime} J^{\prime \prime}}$ is the energy of the emitted photon between the rotational levels $J^{\prime}$, $J^{\prime \prime}$.

The quantities in equation (5) are given by the following equations :

$$
N_{J^{\prime}}=\left(2 J^{\prime}+1\right) \exp -B^{\prime} h c J^{\prime}\left(J^{\prime}+1\right) / k T_{\mathrm{R}}
$$

where $T_{\mathrm{R}}$ is the $\mathrm{CN}$ rotational temperature and
$B^{\prime}$ is the rotational constant [9] and $h, c, k$ are the usual atomic constants.

$$
A_{J^{\prime} J^{\prime \prime}}=S_{J^{\prime}}^{\mathrm{P}} / 2 J^{\prime}+1
$$

with $S_{J^{\prime}}^{\mathrm{P}}=J^{\prime}+1$ for the P-branch of a ${ }^{2} \Sigma^{2} \Sigma$ transition [9].

It can be deduced from equations (5)-(7) that :

$$
\log \left(\frac{I_{J^{\prime}}^{\mathrm{P}}}{J^{\prime}+1}\right)=-\frac{B^{\prime} h c}{k T_{\mathrm{R}}} J^{\prime}\left(J^{\prime}+1\right)
$$

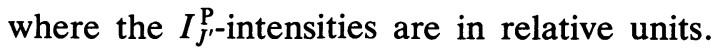

For the $\mathrm{CN} \quad\left(\mathrm{B}^{2} \Sigma, \quad V^{\prime}=0\right), \quad B^{\prime} h c / k T_{\mathrm{R}}=$ $2.82 / T_{\mathrm{R}}$, where $T_{\mathrm{R}}$ is expressed in Kelvin.

From the rotational spectrum of figure 3 (argon, 20 Torr and $5 \mathrm{~W}$ ), a Boltzmann distribution of rotational intensities, corresponding to a rotational temperature $T_{\mathrm{R}}=380-400 \mathrm{~K}$ has been found. At low microwave power, the argon gas temperature is expected to be close to the room temperature, thus the rotational temperature of $\mathrm{CN}$ impurity in argon is also expected to be the room temperature.

Thus the $\mathrm{CN}$ rotational temperature can be chosen to determine the neutral gas temperature. The $\mathrm{CN}$ rotational temperatures $T_{\mathrm{R}}$ are reported in figure 4 . Under our experimental conditions $T_{\mathrm{R}}$ ranges from $380 \mathrm{~K}(20$ Torr, $5 \mathrm{~W})$ to $840 \mathrm{~K}$ ( 300 Torr, $30 \mathrm{~W}$ ). In the following, these temperature values have been used to calculate the Doppler broadening of the absorption line profiles.

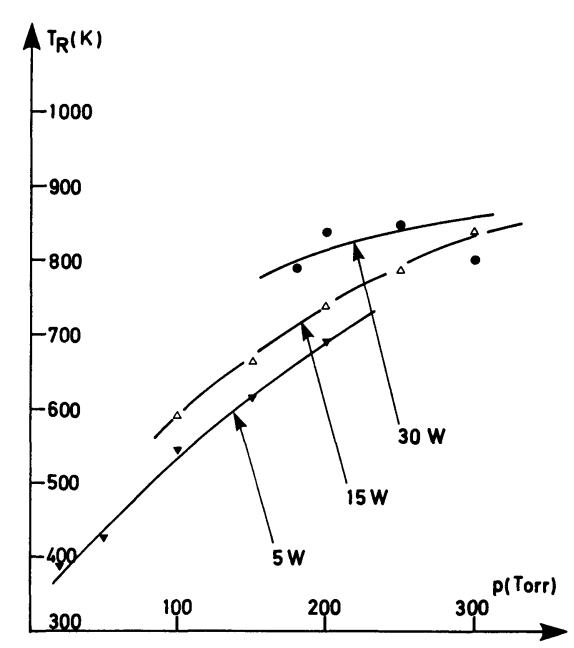

Fig. 4. - CN-rotational temperature versus the argon pressure for several input microwave powers.

\section{Concentration of the $\operatorname{Ar}\left({ }^{3} P_{2}\right)$ metastable atoms and electron density.}

5.1 Concentration of metastables. - The $\operatorname{Ar}\left({ }^{3} \mathrm{P}_{2}\right)$ metastable densities have been determined from the measurements of $A_{L}$ and $T_{0}$ for the two 
spectral lines already mentioned $(\lambda=696.5 \mathrm{~nm}$ and $\lambda=706.7 \mathrm{~nm})$. The variations of $\operatorname{Ar}\left({ }^{3} \mathrm{P}_{2}\right)$ concentrations with the gas pressure are reported in figure 5 for several microwave powers between 5 and $30 \mathrm{~W}$. We recall that the metastable concentration $n_{M}$ is an averaged value over the plasma length.

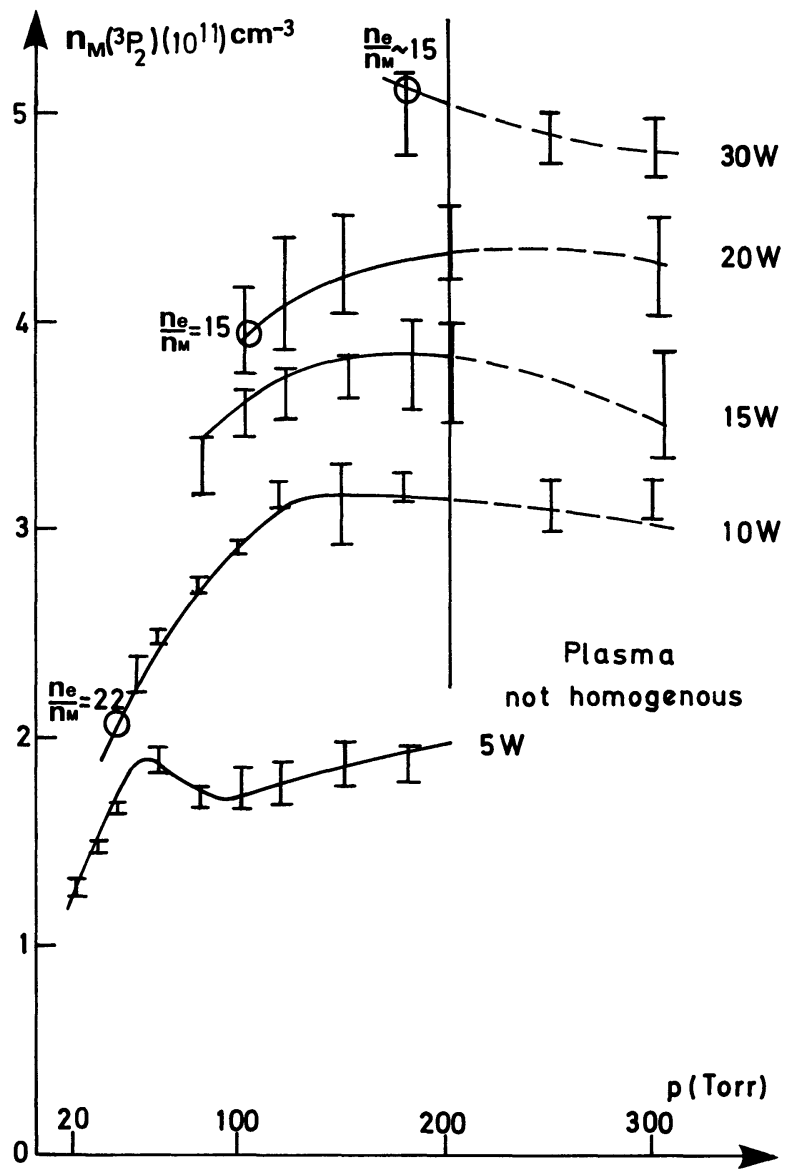

Fig. 5. $-\operatorname{Ar}\left({ }^{3} \mathrm{P}_{2}\right)$ metastable densities versus argon pressure for several input microwave powers. The dashed line indicate heterogeneous plasmas where the $\operatorname{Ar}\left({ }^{3} \mathrm{P}_{2}\right)$ densities are only approximate values. The error bars come from absorption measurements using the $696.5 \mathrm{~nm}$ and $706.7 \mathrm{~nm}$ spectral lines. Precision on the $n_{\mathrm{e}} / n_{\mathrm{M}}$ value of $50 \%$.

These results have been obtained under the following approximations :

i) the central part of the plasma is radially and axially homogeneous (over a diameter equal to that of the incident light beam, i.e. $2 \mathrm{~mm}$ and over its all length $L$ ). Nevertheless, as the pressure is increased up to 200 to 300 Torr, the plasma becomes more and more heterogeneous and does not fill all the tube diameter. Therefore we only have plotted dashed lines in figure 5 because the metastable concentrations determined in the 200-300 Torr range only provide rough estimations ; ii) the absorption length $(L)$ is equal to the glow length and the density of metastables outside the glow region is neglected. Such an approximation weakly overestimates the metastable concentration. For example, at $p=100 \mathrm{~T}$ and $15 \mathrm{~W}$, the loss frequency of $\operatorname{Ar}\left({ }^{3} \mathrm{P}_{2}\right)$ metastable atoms by neutral collisions is $2 \times 10^{4} \mathrm{~s}^{-1}$ [10] giving a length of about $5 \mathrm{~mm}$ in the afterglow. The glow length being $15 \mathrm{~cm}$, the metastable concentration is overestimated of $7 \%$. The incertitude on metastable density values, due to the $A_{L}, \Delta \nu_{\mathrm{D}}^{\mathrm{S}}$ and $T_{0}$ measurements is estimated to $30 \%$. Experimental data plotted in figure 5 provide a good agreement between the metastable concentrations obtained from the absorption measurements on the two wavelengths (inside the error bars). These results also show a trend of metastable concentrations to saturate as the pressure increases.

5.2 ELECTRON DENSITY. - The electron density $\left(n_{\mathrm{e}}\right)$ has been measured from the phase variations of the electric field outside the discharge tube [5]. However, as shown in figure 1 , the discharge is symmetric on both sides of the waveguide, thus the plasma length outside the waveguide is too short for the phase measurements. Therefore, they have been performed in a discharge created only on one side of the guide (a short circuit prevents the plasma to be created on the other side). The electron density increases from the end of the plasma column towards the excitation gap. An increase of the input microwave power only shifts the tip of the plasma away the gap and does not change the axial gradient of electron density. For example, at 50 Torr, we find for $P_{\text {in }}=20 \mathrm{~W}, L=20 \mathrm{~cm}, \quad n_{\mathrm{e}}($ gap $)=2.6 \times$ $10^{13} \mathrm{~cm}^{-3}$ and for $P_{\text {in }}=200 \mathrm{~W}, L=60 \mathrm{~cm}$, $n_{\mathrm{e}}($ gap $)=9 \times 10^{13} \mathrm{~cm}^{-3}$.

As the measured metastable concentrations are longitudinally averaged values $\bar{n}_{\mathrm{M}}$, we have to compare them to longitudinally averaged electron densities $\bar{n}_{\mathrm{e}}$. Obviously, these averaged electron densities also increase with the microwave power. For example, under the above conditions we respectively find $\quad \bar{n}_{\mathrm{e}}(20 \mathrm{~W})=1.3 \times 10^{13} \mathrm{~cm}^{-3}$ and $\bar{n}_{\mathrm{e}}(200 \mathrm{~W})=4.5 \times 10^{13} \mathrm{~cm}^{-3}$. For a constant plas-

Table I. - Variations of input microwave power $P_{\text {in }}$, electron density $\bar{n}_{\mathrm{e}}$ and metastable density $\bar{n}_{\mathrm{M}}$ as a function of the gas pressure $p$ for a constant plasma length $L=15 \mathrm{~cm}$. Incertitudes of $30 \%$ on metastable densities and of $20 \%$ on electron densities.

$\begin{array}{lccc}p \text { (Torr) } & 50 & 100 & 200 \\ P_{\text {in }}(\mathrm{W}) & 10 & 20 & 30 \\ \bar{n}_{\mathrm{e}}\left(\mathrm{cm}^{-3}\right) & 5 \times 10^{12} & 6 \times 10^{12} & 8 \times 10^{12} \\ \bar{n}_{\mathrm{M}}\left(\mathrm{cm}^{-3}\right) & 2.25 \times 10^{11} & 3.9 \times 10^{11} & 5.2 \times 10^{11} \\ \bar{n}_{\mathrm{M}} / \bar{n}_{\mathrm{e}} & 0.045 & 0.065 & 0.065\end{array}$


ma length, the microwave power and the electron density are increasing with the pressure. In table I, we have reported, for a constant plasma length $L=15 \mathrm{~cm}$, the variations of $\bar{n}_{\mathrm{e}}, \bar{n}_{\mathrm{M}}$ and the ratio $\bar{n}_{\mathrm{M}} / \bar{n}_{\mathrm{e}}$ which the trend is to exhibit a saturation as the pressure increases.

From these measurements, we deduce that the $n_{\mathrm{M}} / n_{\mathrm{e}}$ ratio keeps a nearly constant value of $0.065( \pm 0.03)$ between 100 and 200 torr. Ratios less than 1 have also been obtained in a $2450 \mathrm{MHz}$ microwave discharge at low argon pressure [11]. For example with $p_{\mathrm{Ar}}=0.2$ Torr, $\bar{n}_{\mathrm{M}} / \bar{n}_{\mathrm{e}}=0.4\left(\bar{n}_{\mathrm{M}}=\right.$ $\left.1.5 \times 10^{11} \mathrm{~cm}^{-3}, \bar{n}_{\mathrm{e}}=4 \times 10^{11} \mathrm{~cm}^{-3}\right)$.

\section{Discussion and conclusion.}

Concentrations of argon metastable atoms have been measured in a $2.45 \mathrm{GHz}$ microwave discharge at high pressures 20-300 Torr. The resonant optical absorption method has been employed by using an external optical source which line profiles have been before measured.

In order to know the absorption line profile which is produced by Doppler and pressure effects, the gas temperature has been measured from the rotational emission of $\mathrm{CN}$ impurity in the argon plasma. Temperature values from $380 \mathrm{~K}$ ( 20 Torr, $5 \mathrm{~W}$ ) to $840 \mathrm{~K}$ (300 Torr, $30 \mathrm{~W}$ ) have been obtained.

Such $\mathrm{CN}$ impurity emission has also been observed in $13.6 \mathrm{MHz}$ argon discharges at low pressures (12 Torr) with density of metastable atoms in the order of $10^{11} \mathrm{~cm}^{-3}$ [12].

According to the high electron density in the present experimental conditions $\left(n_{\mathrm{e}}=3 \times 10^{12}-2 \times\right.$ $\left.10^{13} \mathrm{~cm}^{-3}\right)$, the $\operatorname{Ar}\left({ }^{3} \mathrm{P}_{2}\right)$ metastable atoms are mainly created by electron collisions from the argon ground state and destroyed by electron collisions towards upper excited or ionized levels [11]. Thus, the $\operatorname{Ar}\left({ }^{3} \mathrm{P}_{2}\right)$ loss term by excitation transfer on $\mathrm{CN}$ radicals can be neglected with regards to the loss term by electron collisions.

The measurements of $\operatorname{Ar}\left({ }^{3} \mathrm{P}_{2}\right)$ density had previously been performed in microwave discharges created by surface wave at $2450 \mathrm{MHz}$ either at low pressure $(p<1$ torr, [11]), or at atmospheric pressure [13]. At low pressure, $\operatorname{Ar}\left({ }^{3} \mathrm{P}_{2}\right)$ densities of $1-2 \times 10^{11} \mathrm{~cm}^{-3}$ were measured for $n_{\mathrm{e}}$ in the range $10^{10}-10^{12} \mathrm{~cm}^{-3}$ [11]. In atmospheric microwave discharges the $\operatorname{Ar}\left({ }^{3} \mathrm{P}_{2}\right)$ densities, slightly less than $10^{12} \mathrm{~cm}^{-3}$ have been measured for $n_{\mathrm{e}}$ in the range $10^{14}-10^{15} \mathrm{~cm}^{-3}$ [13]. Thus, our experiments at medium pressures, provide the continuity between low and atmospheric pressure discharges.

The results obtained all over the pressure range emphasize the trend of $\operatorname{Ar}\left({ }^{3} \mathrm{P}_{2}\right)$ metastable density to the saturation as the pressure and, simultaneously, the electron density increase [4], explaining the decay of the ratio $n_{\mathrm{M}} / n_{\mathrm{e}}$.

\section{References}

[1] Moisan, M. et al., Revue Phys. Appl. 17 (1982) 707.

[2] Nghiem, P. et al., J. Appl. Phys. 53 (1982) 2920.

[3] Ferreira, C. M., J. Phys. D 14 (1981) 1811.

[4] Pantel, R., Ricard, A., Moisan, M., Beitr. Plasmas Phys. 23 (1983) 561 ;

Moisan, M., Pantel, R., Ricard, A., Can. J. Phys. 60 (1982) 379.

[5] Granier, A., Gousset, G., Leprince, P., Marec, J., Revue Phys. Appl. 22 (1987) 999.

[6] Mitchell, A., Zemansky, M., Resonance radiation and Excited Atoms (Univ. Presse Cambridge) 1977.

[7] Vallee, O., Ranson, P., Chapelle, J., J.Q.S.R.T. 19 (1977) 327.
[8] Tachibane, K., Harima, H., Orano, Y., J. Phys. B 15 (1982) 3169.

[9] Herzberg, G., Spectra of Diatomic Molecules (North Holland Publ.) 1950.

[10] Delcroix, J. L., Ferreira, C. M., Ricard, A., Metastable atoms and Molecules in Ionized gas, in Principles of Laser Plasmas, Ed. G. Bekefi (John Wiley) 1976 pp. 159-235.

[11] Ricard, A. et al., Can J. Phys. (to be published 1988).

[12] Ceccaroli, B. and Ricard, A., Revue Phys. Appl. 21 (1986) 197.

[13] Moussounda, P. S., Ranson, P., Mermet, J. M., Spectrochim. Acta B 40 (1985) 641. 